\title{
A Comparison of Cytokine Profiles of Chronic Fatigue Syndrome/Myalgic Encephalomyelitis and Multiple Sclerosis Patients
}

\author{
Naomi Wong1, Thao Nguyen1, Ekua Weba Brenu1, Simon Broadley ${ }^{2,3}$, Donald Staines, ${ }^{1,2}$ \\ Sonya Marshall-Gradisnik ${ }^{1,2}$ \\ ${ }^{1}$ National Centre for Neuroimmunology and Emerging Diseases, Griffith Health Centre, School of Medical \\ Science, Griffith University, Gold Coast, Australia \\ ${ }^{2}$ School of Medicine, Gold Coast Campus, Griffith University, Gold Coast, Australia \\ ${ }^{3}$ Department of Neurology, Gold Coast University Hospital, Gold Coast, Australia \\ Email: s.marshall-gradisnik@griffith.edu.au
}

Received 15 September 2015; accepted 26 October 2015; published 29 October 2015

Copyright (C) 2015 by authors and Scientific Research Publishing Inc.

This work is licensed under the Creative Commons Attribution International License (CC BY). http://creativecommons.org/licenses/by/4.0/

\section{Open Access}

\section{Abstract}

Background: Chronic Fatigue Syndrome, also known as Myalgic Encephalomyelitis (CFS/ME), is a debilitating condition that presents with a range of symptoms, including fatigue, cognitive dysfunction, muscular and joint pain, and may be immune-mediated. In particular, patients exhibit abnormal cytokine expression. Similarly, in Multiple Sclerosis (MS), patients display neuroimmunological symptoms, and abnormal cytokine expression, with some overlap in symptomology with CFS/ME. The purpose of this study was to compare Th1, Th2, Th17 cytokines, inflammatory cytokines and chemokines, in healthy controls, CFS/ME and MS patients. Methods: Serum samples were collected from healthy controls $(n=16$, mean age $=50 \pm 11.85$ years), CFS $/$ ME patients $(n=$ 16 , mean age $=49.88 \pm 9.54$ years $)$ and MS patients $(n=11$, mean age $=52.75 \pm 12.81$ years $)$. The concentrations of 27 cytokines (IFN- $\gamma$, TNF- $\alpha$, IL-12, IL-2, IL-1 $\beta$, IL-4, IL-6, IL-10, IL-13, IL-5, IL-17, IL-1ra, IL-7, IL-8, IL-9, eotaxin, IP-10, MCP-1, MIP1 $\alpha$, MIP1 $\beta$, PDGF-bb, RANTES, basic FGF, GCSF, GMCSF, VEGF and IL-15) were measured using a Bio-Plex Pro ${ }^{\text {TM }}$ kit. Results: IFN- $\gamma$, IL-10 and IL-5 were significantly higher in the serum of both CFS/ME and MS patients compared to the healthy controls ( $p \leq 0.041)$. However, only the MS patients had significantly elevated levels of IL-12, IL-1 $\beta$, IL-4, IL-13, IL-6, IL-17, IL-1ra, IL-7, IL-9, eotaxin, IL-10, MIP1 $\alpha$, basic FGF, GCSF and VEGF compared to the CFS/ME patients and controls $(p \leq 0.04)$. There were no significant differences between groups for IL-8, MCP-1, MIP1 $\beta$, RANTES, GMCSF, TNF- $\alpha$, and IL-2. Conclusion: CFS/ME and MS patients both displayed abnormal cytokine levels, with dual expression of Th1 and Th2 cytokines. Further research into cytokines such as IFN- $\gamma$, IL-10 and IL-5, with the use of a specific CFS/ME 
case definition and sensitive cytokine assays, is required to improve the understanding of the pathophysiology of CFS/ME.

\author{
Keywords
}

\author{
Chronic Fatigue Syndrome, Multiple Sclerosis, Immunology, Cytokine
}

\title{
1. Introduction
}

Chronic Fatigue Syndrome (CFS/ME) is a debilitating illness described as fatigue lasting more than 6 months, accompanied by various symptoms including cognitive difficulties, sore throat, muscle or joint pain, and headaches [1]. As CFS/ME patients commonly present with symptoms that indicate immune response abnormalities, such as flu-like symptoms, cytokine expression has been an area of interest for researchers. Cytokines are important in the function, activation and suppression of immune cells [2], and hence abnormalities in their expression may affect immune cell function. Earlier cytokine studies of CFS/ME have shown contradictory results, with observations of both significant differences and no significant differences in cytokine levels in serum [3][5]. Significant upregulation of Th2 cytokines such as IL-4, IL-5, IL-10 and IL-6 has been reported [6]-[10]; conversely other studies have reported increased levels of Th1 cytokines including IFN- $\gamma$, TNF- $\alpha$, IL-2, IL-12, and IL-1 $\beta$ [6] [8]-[12].

Multiple Sclerosis (MS) is a chronic disease targeting the central nervous system and believed to be immunological in nature, resulting in demyelination in the brain and spinal cord, particularly in the white matter [13]. Common symptoms include visual impairment, sensory symptoms, weakness, impaired balance and fatigue. Later in the disease impairment of higher cognitive functions is common. MS can present in relapsing-remitting form, where periods of relapse, characterized by worsening of disease symptoms are followed by periods of recovery. Acute and chronic pain can be a feature of MS [14]-[16]. The profiles of Th1, Th2, Th17 cytokines, as well as other cytokines and chemokines, have also been investigated in MS; however studies have yielded inconsistent results. IFN- $\gamma$ has been found to be contributory in the disease pathophysiology of MS, as its administration has been associated with relapse and exacerbation of symptoms [17] [18]. TNF- $\alpha$ expression is thought to be correlated with disease severity, with TNF- $\alpha$ levels increasing throughout the clinical course of MS [19] [20]. High levels of IL-4 have been observed in both acute relapses and in remission in MS [21] [22], with increased secretion also being observed [23]. Elevated serum levels of IL-6 have been observed in MS patients [24] [25]. Studies involving IL-10 have indicated an influential role of IL-10 in the recovery of MS, with levels decreasing during periods of relapse, and increasing when patients are in remission [26]-[29].

Cytokine expression abnormalities are exhibited in both CFS/ME and MS, with dual expression of Th1/Th2 cytokines. However, previous studies of cytokines in CFS/ME have been inconclusive. The objective of this study therefore is to investigate and compare the cytokine profiles of healthy controls, CFS/ME and MS patients.

\section{Methods}

\subsection{Participants}

A cross-sectional case-control study design was used, and samples were obtained from a previous large prospective cohort study. Ethics approval was granted by the Griffith University Human Research Ethics Committee (EC00162), reference number MSC 22/12/HREC. A participant information sheet was provided and written consent was obtained from all participants. CFS/ME patients were classified using the ICC definition [1]. MS patients met the 2010 revision of the McDonald criteria [30] and assessed by a consultant neurologist.

\subsection{Measurement of Cytokines}

A Bio-Plex Pro ${ }^{\mathrm{TM}}$ kit (Bio-Plex Pro Human 27-plex Assay, Bio-Rad, Hercules, CA, USA) was used to measure serum cytokine concentrations of 27 cytokines, as per manufacturer's instructions. Cytokines IFN- $\gamma$, TNF- $\alpha$, IL-12, IL-2, IL-1 $\beta$, IL-4, IL-6, IL-10, IL-13, IL-5, IL-17, IL-1ra, IL-7, IL-8, IL-9, eotaxin, IP-10, MCP-1, 
MIP1 $\alpha$, MIP1 $\beta$, PDGF-bb, RANTES, basic FGF, GCSF, GMCSF, VEGF and IL-15 were assessed in duplicates. Serum was acquired from peripheral whole blood, diluted by a factor of 1:4, and then incubated in a 96-well plate for 30 minutes with capture antibody-coupled magnetic beads. During the incubation the plate was sealed and protected from light with aluminum foil, and placed on a shaker at $850 \pm 50 \mathrm{rpm}$. The plate was then washed with buffer using a Bio-Plex Pro wash station. The plate was then incubated with biotinylated detection antibodies for 27 cytokines as previously mentioned for 30 minutes. After washing, 1× SA-PE florescence was added and the plate was incubated for 10 minutes. The plate was then washed and assay buffer was added to the wells to re-suspend the magnetic beads. The plate was incubated for 30 seconds prior to analysis. Bio-Plex MAGPIX software was used to assess the concentration of the 27 cytokines.

\subsection{Statistical Analysis}

Results were statistically analysed using SPSS. Duplicated measurements were averaged, and outliers were excluded [31]. For data that was normally distributed ANOVA was used to assess significant differences between control, CFS/ME and MS patients for each cytokine. The Post hoc tests used were Bonferroni for homogeneity of variances, and Games-Howell where there was heterogeneity of variances. For data that was not normally distributed, Kruskal-Wallis test was used to find significant differences, and the Mann-Whitney U test was used to find significant differences between the groups. Criterion of significance was set at an alpha level of $\mathrm{p} \leq 0.05$.

\section{Results}

\subsection{Patient Demographics}

The mean ( \pm standard deviation) ages for the healthy controls, CFS/ME patients, and MS patients were $50 \pm$ 11.846, $50 \pm 9.542$, and $58 \pm 11.990$ years respectively (Table 1). There was no significant age difference between the three groups. Female participants percentages were $50 \%, 68.8 \%$, and $72.7 \%$ respectively.

MS patients were further categorized by disease subtype and current treatments (see Table 2). MS patients were predominantly relapsing-remitting patients (63.6\%), and $18.2 \%$ were secondary-progressive patients. IFN- $\beta$ was the most common treatment, used by $54.5 \%$ of MS patients, while $36.4 \%$ of MS patients were not undergoing therapeutic treatment.

Table 1. Patient characteristics.

\begin{tabular}{cccc}
\hline Characteristic & $\begin{array}{c}\text { Control (n= 16) } \\
\text { mean (SD) }\end{array}$ & $\begin{array}{c}\text { CFS/ME patients (n= 16) } \\
\text { mean (SD) }\end{array}$ & $\begin{array}{c}\text { MS patients (n= 11) } \\
\text { mean (SD) }\end{array}$ \\
\hline Age & $50.06(11.846)$ & $49.88(9.542)$ & $57.82(11.990)$ \\
WBC & $5.56 \times 10^{6}(1.602)$ & $5.17 \times 10^{6}(1.552)$ & $7.53 \times 10^{6}(1.161)$ \\
\hline Gender & $\begin{array}{c}\text { Control }(\mathbf{n}=\mathbf{1 6}) \\
\mathbf{N}(\mathbf{\%})\end{array}$ & $\begin{array}{c}\text { CFS/ME patients }(\mathbf{n}=\mathbf{1 6}) \\
\mathbf{N}(\mathbf{\%})\end{array}$ & $\begin{array}{c}\text { MS patients (n }=\mathbf{1 1}) \\
\mathbf{N}(\%)\end{array}$ \\
\hline Female & $8(50.0 \%)$ & $11(68.8 \%)$ & $8(72.7 \%)$ \\
Male & $7(43.8 \%)$ & $5(31.3 \%)$ & $3(27.3 \%)$ \\
\hline
\end{tabular}

Table 2. MS patient characteristics; subtype of disease and current drug treatments.

\begin{tabular}{lc}
\hline Characteristic & MS patients N (\%) \\
Type of disease & \\
Clinically isolated syndrome & $1(9.1 \%)$ \\
Relapsing remitting & $7(63.6 \%)$ \\
Primary progressive & $1(9.1 \%)$ \\
Secondary progressive & $2(18.2 \%)$ \\
Treatment & \\
None & $4(36.4 \%)$ \\
IFN- $\beta$ & $6(54.5 \%)$ \\
Glatiramer acetate & $1(9.1 \%)$ \\
\hline
\end{tabular}


CFS/ME patients are often undergoing therapeutic treatment to manage their symptoms. Medications taken by CFS/ME patients were divided into categories (see Table 3) including anti-inflammatory, anti-microbial, anticonvulsants, psychoactive drugs (which comprised anti-depressants, and anti-anxiety medications), analgesics, natural supplements and vitamins, and other (blood pressure medications, anticoagulants, or digestive medications).

\subsection{Analysis of Th1 Cytokine}

T helper (Th) 1 cytokines assessed included IFN- $\gamma$, TNF- $\alpha$, IL-12, IL-1 $\beta$ and IL-2 (see Figure 1). For IFN- $\gamma$,

Table 3. Medications of CFS/ME patients.

\begin{tabular}{|c|c|c|c|}
\hline Medications & $\begin{array}{c}\text { No } \\
\text { N (\%) }\end{array}$ & $\begin{array}{c}\text { Yes } \\
\text { N (\%) }\end{array}$ & $\begin{array}{c}\geq 2 \text { drugs of that type } \\
\text { N (\%) }\end{array}$ \\
\hline Anti-inflammatory & $10(62.5 \%)$ & $4(25 \%)$ & $2(12.5 \%)$ \\
\hline Anti-microbial & $15(93.8 \%)$ & $1(6.3 \%)$ & - \\
\hline Psychoactive drugs (anti-depression/anxiety etc.) & $7(43.8 \%)$ & $4(25 \%)$ & $5(31.3 \%)$ \\
\hline Analgesic & $11(68.8 \%)$ & $4(25 \%)$ & $1(6.3 \%)$ \\
\hline Natural/supplements/vitamins & $13(81.3 \%)$ & $1(6.3 \%)$ & $2(12.5 \%)$ \\
\hline Other (proton inhibitors, BP medication, digestive, anticoagulants) & $10(62.5 \%)$ & $4(25 \%)$ & $2(12.5 \%)$ \\
\hline
\end{tabular}

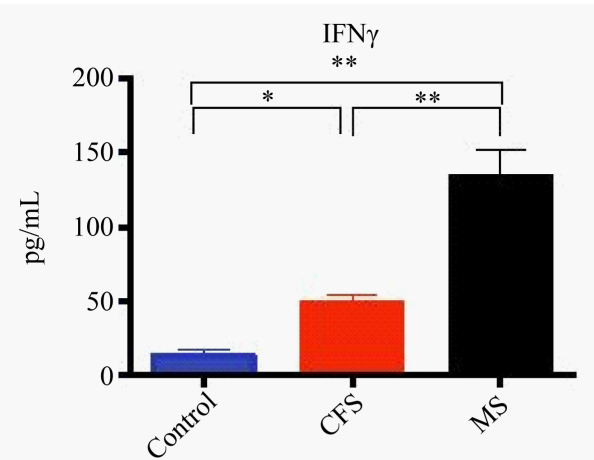

(a)

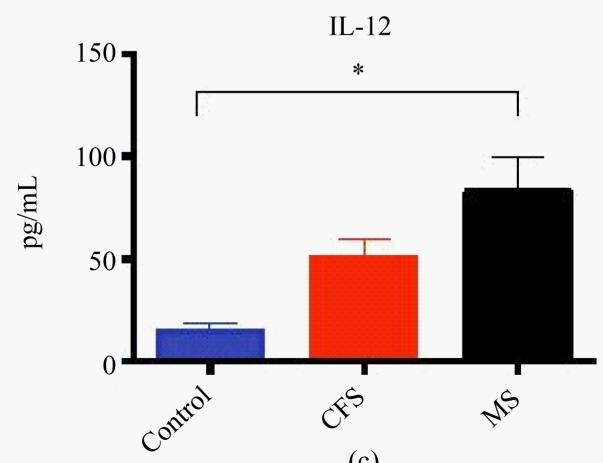

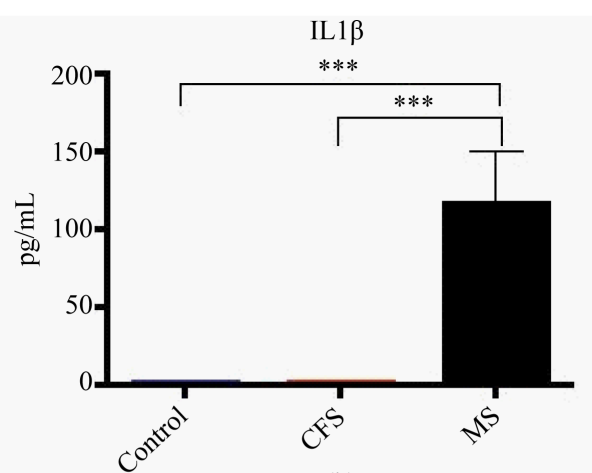

(b)

Figure 1. Comparison of serum Th1 cytokines in healthy controls, CFS/ME patients and MS patients. (a) IFN$\gamma$ was significantly different between groups ( $\mathrm{p} \leq 0.041)$, where CFS/ME and MS patients both displayed elevated serum levels; (b) IL- $1 \beta$ was significantly elevated in MS patients, compared with CFS/ME patients and controls ( $\mathrm{p} \leq 0.001$ ); (c) IL-12 was significantly elevated in in MS patients compared with controls ( $\mathrm{p} \leq 0.021$ ), with no significant difference between CFS/ME and MS patients. * Denotes a statistically significant difference where $\mathrm{p} \leq 0.05,{ }^{* * *}$ Denotes where $\mathrm{p} \leq 0.01$, and ${ }^{* * * *}$ Denotes where $\mathrm{p} \leq 0.001$. Data is represented as mean \pm SEM in pg/mL. CFS/ME = Chronic Fatigue Syndrome/Myalgic Encephalomyelitis; MS = Multiple Sclerosis; IFN- $\gamma$ = interferon gamma; IL = interleukin, SEM = standard error of the mean. 
CFS/ME patients had significantly higher serum levels than controls $(\mathrm{p}=0.041)$, and MS also had significantly higher serum levels compared with control $(\mathrm{p}=0.002)$. There was a significant difference between CFS/ME and MS ( $p=0.006)$. There was no significant difference in level of TNF- $\alpha$ between groups. IL-12 and IL- $1 \beta$ were both significantly higher in MS $(\mathrm{p} \leq 0.021)$ than in CFS/ME and control. IL-2 was not significantly different between groups.

\subsection{Analysis of Th2 and Th17 Cytokine}

Th2 cytokines that were assessed included IL-4, IL-6, IL-10, IL-13, and IL-5 (see Figure 2). Serum IL-4 and
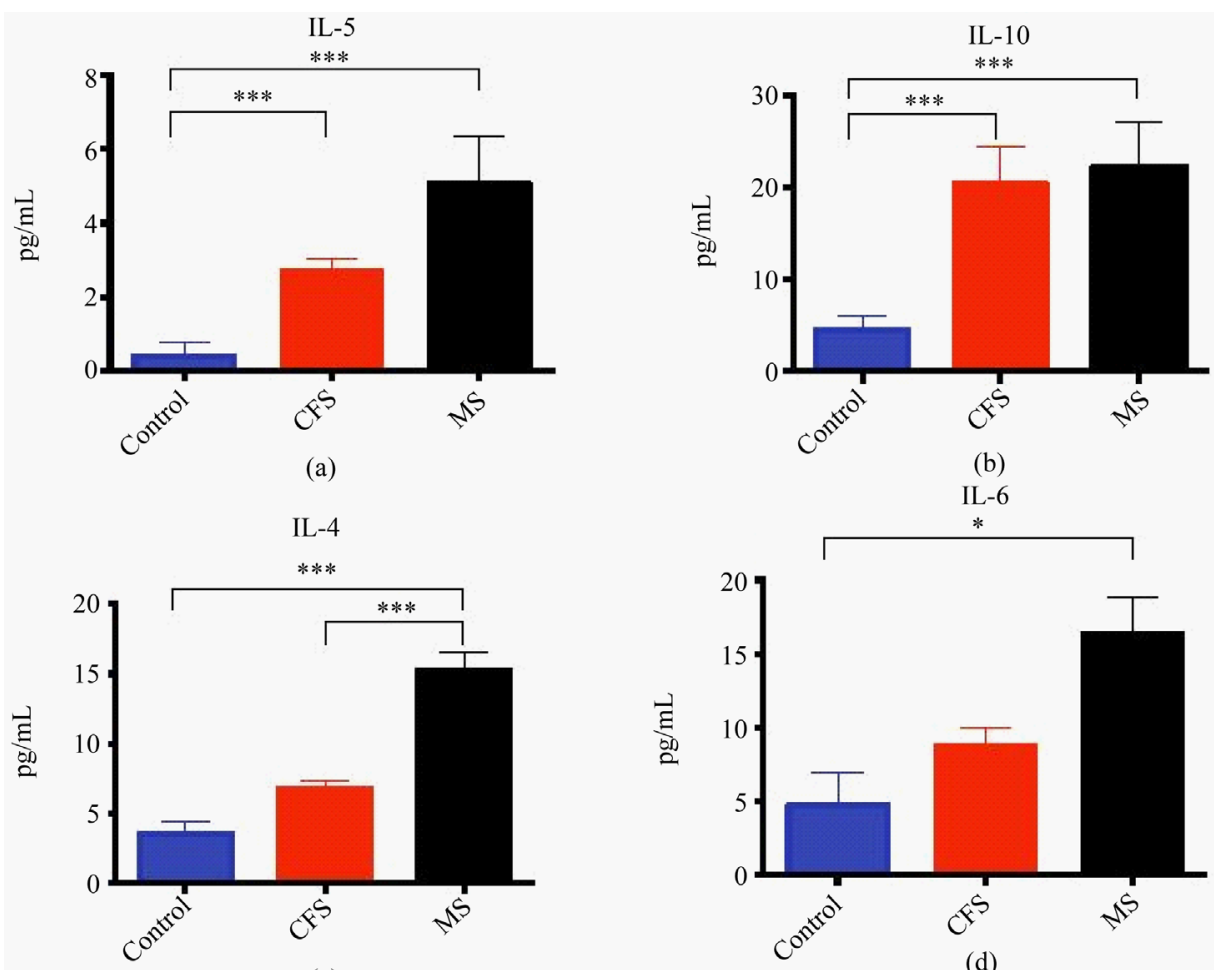

(c)
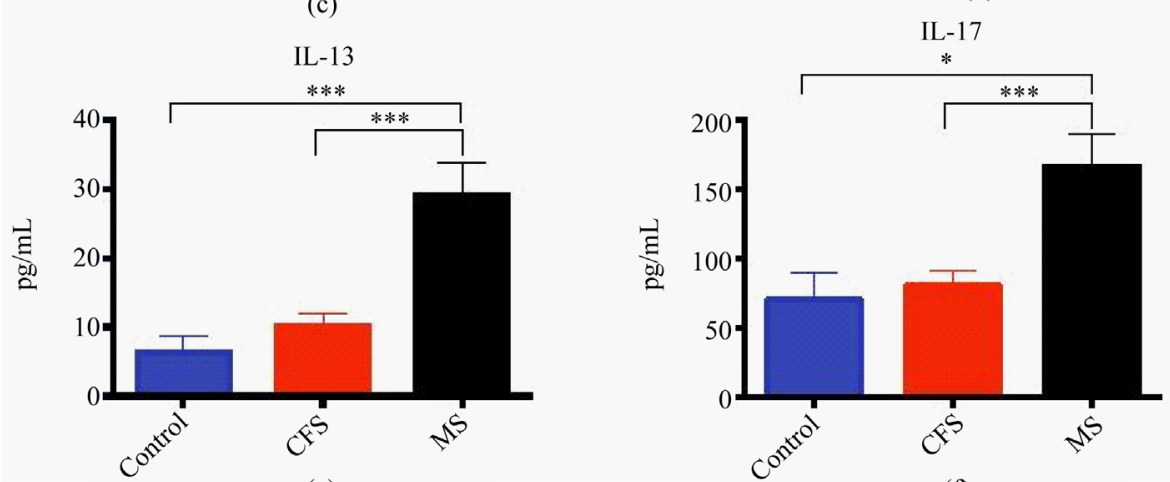

(e)

(f)

Figure 2. Comparison of serum Th2 and Th17 cytokines in healthy controls, CFS/ME patients, and MS patients. (a) IL-5 was significantly different across groups, with CFS/ME and MS patients exhibiting significantly elevated serum levels ( $\mathrm{p} \leq 0.001$ ); (b) IL-10 was also significantly different across groups, with CFS/ME and MS patients exhibiting significantly elevated serum levels ( $\leq \leq 0.001)$; (c) IL-4 was significantly elevated in only MS patients ( $\mathrm{p} \leq 0.001$ ); (d) IL-6 was significantly elevated in MS patients ( $\mathrm{p} \leq 0.049$ ); (e) IL-13 was significantly elevated in MS patients ( $\mathrm{p} \leq 0.001)$; (f) IL-17 was significantly elevated in MS patients $(\mathrm{p} \leq 0.033$ ). *Denotes a statistically significant difference where $\mathrm{p} \leq 0.05$, ${ }^{* *}$ Denotes where $\mathrm{p} \leq 0.01$, and ${ }^{* * * *}$ Denotes where $\mathrm{p} \leq 0.001$. Data is represented as mean $\pm \mathrm{SEM}$ in $\mathrm{pg} / \mathrm{mL}$. CFS/ME = Chronic Fatigue Syndrome/Myalgic Encephalomyelitis; MS = Multiple Sclerosis; IL = interleukin, SEM = standard error of the mean. 
IL-13 was significantly elevated in MS compared with CFS/ME and control ( $\mathrm{p} \leq 0.001)$, and CFS/ME and control were not significantly different. IL-6 was also significantly higher in MS patients compared with control (p $=0.049$ ), with no significant difference between MS and CFS/ME patients, and CFS/ME and control groups. However for IL-10, CFS/ME and MS patients were both significantly elevated compared to the control ( $\mathrm{p} \leq$ 0.001), with no significant difference between the two groups. IL-5 was also significantly higher in both MS and CFS/ME compared with controls ( $\leq 0.001$ ), although there was no significant difference between these two groups. IL-17 was significantly different in MS patients compared to CFS/ME $(\mathrm{p}=0.001)$ and control $(\mathrm{p}=$ 0.033 ) groups.

\subsection{Analysis of Other Cytokine}

MS samples also had significantly higher levels of IL-1ra, IL-7, IL-9, eotaxin, IP-10, MIP1 $\alpha$, basic FGF, and GCSF ( $\mathrm{p} \leq$ 0.035), while CFS/ME and control samples were not significantly different (see Figure 3). There

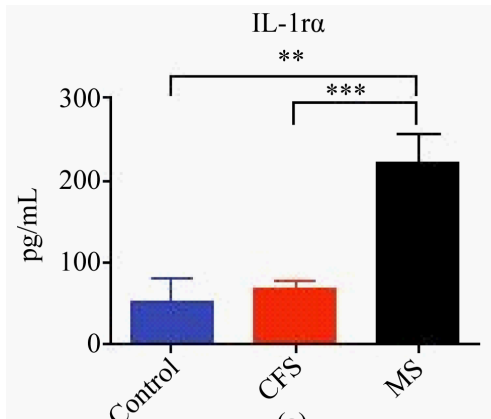

(a)

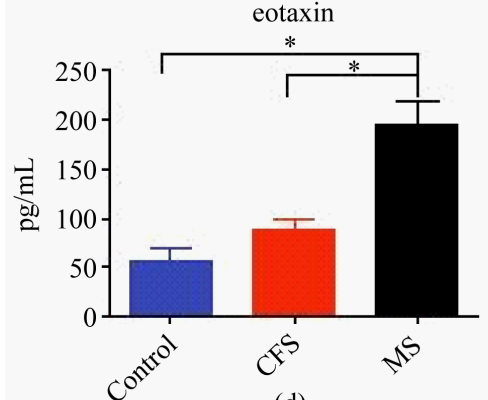

(d)

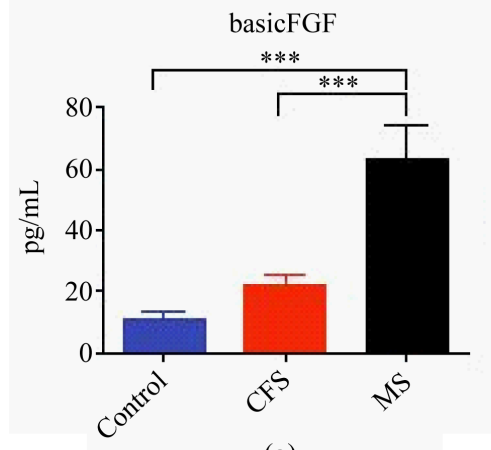

(g)
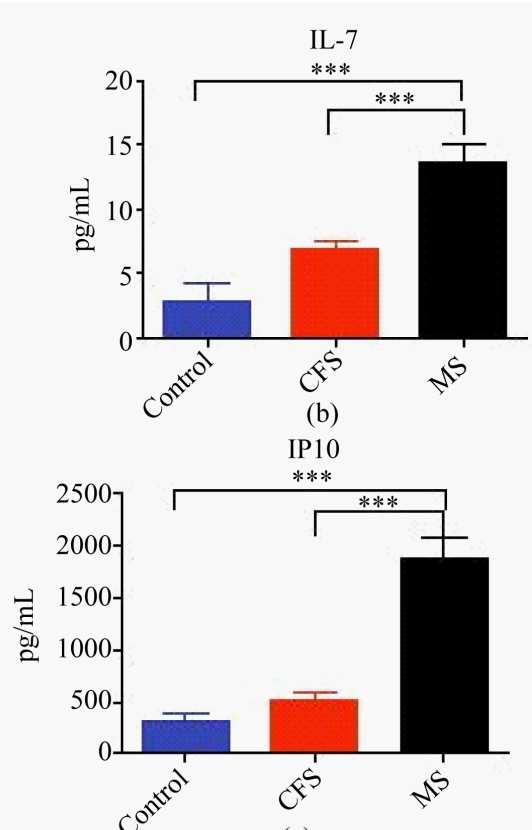

(e)

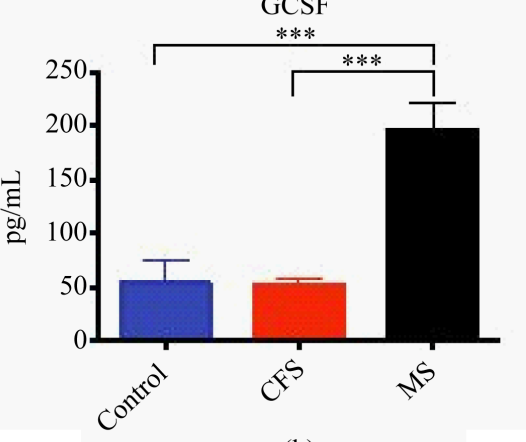

(h)

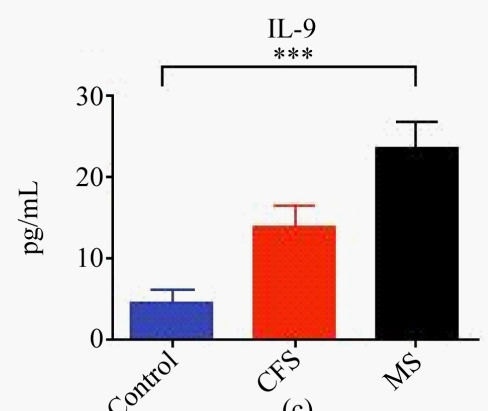

(c)

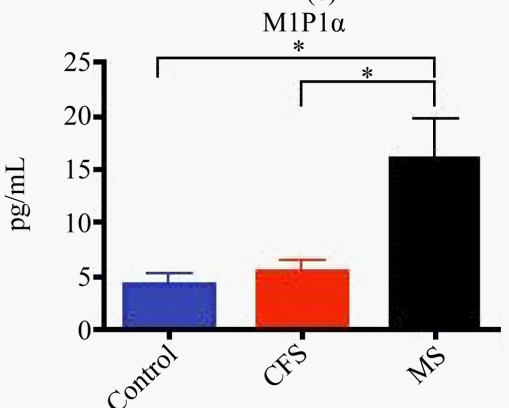

(f)

Figure 3. Comparison of pro-, anti-inflammatory cytokines, and chemokines in healthy controls,CFS/ME patients, and MS patients. (a) IL-1r $\alpha$ was significantly elevated in MS patients ( $\mathrm{p} \leq 0.003$ ); (b) IL-7 was significantly elevated in MS patients ( $\mathrm{p} \leq 0.001)$; (c) IL-9 was significantly elevated in MS patients ( $\leq 0.001)$; (d)-(h) MS patients exhibited significantly elevated levels of eotaxin ( $p \leq 0.026)$, IP-10 ( $\leq 0.001)$, MIP- $1 \alpha(p \leq 0.035)$, basic FGF $(p \leq 0.001)$, GCSF $(p \leq 0.001)$. ${ }^{*}$ Denotes a statistically significant difference where $p \leq 0.05,{ }^{* * *}$ Denotes where $p \leq 0.01$, and ${ }^{* * * *}$ Denotes where $p \leq 0.001$. Data is represented as mean \pm SEM in pg/mL. CFS/ME = Chronic Fatigue Syndrome/Myalgic Encephalomyelitis; MS = Multiple Sclerosis; IL = interleukin; IP = interferon gamma induced protein; MIP = macrophage inflammatory protein; FGF = fibroblast growth factor; GCSF = granulocyte colony stimulating factor; SEM = standard error of the mean. 
was no significant difference between the three groups for IL-8, MCP-1, MIP-1 $\beta$, PDGF-bb, RANTES, VEGF and GMCSF serum levels.

\subsection{Analysis of Effect of Medications}

In order to test the effect of MS therapeutic treatment on serum cytokine levels, ANOVA and Bonferroni post hoc tests were performed between drug groups for each cytokine. There was no significant difference between MS patients undergoing treatment compared with no treatment for any of the cytokines tested. Similarly, the medications for CFS/ME patients were analysed, with no significant effect found.

\section{Discussion}

This study simultaneously compared the cytokine profiles of healthy controls, CFS/ME patients and MS patients, and found significant differences in IFN- $\gamma$, IL-10, Il-5, IL-12, IL-1 $\beta$, IL-4, IL-13, IL-6, IL-17, IL-1r $\alpha$, IL-7, IL-9, eotaxin, IL-10, MIP-1 $\alpha$, basic FGF, GCSF and VEGF. CFS/ME and MS patients both exhibited significantly elevated levels of IFN- $\gamma$, IL-10 and IL-5, while MS alone exhibited significantly elevated levels of IL-12, IL-1 $\beta$, IL-4, IL-13, IL-6, IL-17, IL-1r $\alpha$, IL-7, IL-9, eotaxin, IL-10, MIP-1 $\alpha$, basic FGF, and GCSF. This comparison with MS may assist in the investigation of the pathophysiology of CFS/ME, as well as contribute to the determination of potential biomarkers for CFS/ME.

\subsection{Th1 Cytokines}

IFN- $\gamma$ plays an immunoregulatory function, enhancing antigen-presentation to lymphocytes and natural killer (NK) cell cytotoxicity [32], and is primarily produced by Th1 cells and NK cells [33]. Production of IFN- $\gamma$ is usually triggered by antigen presentation, and can be stimulated by IL-2 and IL-12, as well as external stimuli such as viral or bacterial infection [33]. Expression of IFN- $\gamma$ largely promotes the differentiation of Th1 cells [34]. CFS/ME patients exhibited significantly elevated levels of IFN- $\gamma$, suggesting Th1 skewing, and supporting previous findings [8] [9], while other studies found no significant difference in IFN- $\gamma$ [6] [10]. Elevated IFN- $\gamma$ levels may suggest an increase in NK cell activation. It has been suggested that an increase in IFN- $\gamma$ may be a result of increased effort to activate NK cells, as numerous CFS/ME studies have found significantly reduced NK cell cytotoxic activity [8] [35]-[38]. MS patients also exhibited significantly elevated levels of serum IFN- $\gamma$ in this study. In experimental autoimmune encephalomyelitis (EAE), the animal model of MS, IFN- $\gamma$ has been associated with disease initiation [39]. IFN- $\gamma$ has also been associated with periods of relapse and worsening of disease symptoms in numerous MS studies [17] [18], indicating a pathological role for IFN- $\gamma$ in MS. Intriguingly, IFN- $\gamma$ is associated with fatigue and depression in MS [40], and IFN- $\gamma$ may contribute in a similar way to the pathophysiology of CFS/ME.

IL-1 $\beta$, a potent inflammatory cytokine, was significantly elevated in MS patients compared to CFS/ME patients and controls. Previous research has demonstrated elevated levels of IL- $1 \beta$ in cerebrospinal fluid correlated with cortical lesion load in MS patients [41], and the cytokine is believed to trigger oligodendrocyte and neurodegeneration [42]. Previous CFS/ME studies also found no significant difference from healthy controls for IL- $1 \beta$ [3]-[5]. However elevated serum levels have also previously been found in CFS/ME [10]. It could be proposed that IL-1 $\beta$ may be the source of some cognitive dysfunction and cortical lesions in CFS/ME patients, as with MS patients, and cerebrospinal fluid levels of CFS/ME patients may be informational.

IL-12 was also significantly elevated in MS patients compared to CFS/ME patients and controls. IL-12 is a pro-inflammatory cytokine which affects the differentiation of Th1 cells and plays an influential role in NK cell activity [43]. The findings of this study complement findings in previous CFS/ME studies [9] [10]. However some other studies have previously found elevated levels in CFS/ME compared to controls [6] [8]. As results have been mixed, it is still unclear as to the role that IL-12 may play in the pathophysiology of CFS/ME, however its elevation could also contribute to NK cell dysfunction, as well as influence the disruption of the Th1 and Th2 cytokine balance. In MS it has been suggested that IL-12 has a pathological role in the initiation of MS, with up regulation of IL-12 present in human MS lesions [44].

MS patients exhibited elevated levels of IFN- $\gamma$, IL- $1 \beta$ and IL-12, indicating a state of inflammation. IL-12 may be influencing the release of IFN- $\gamma$ from NK cells, and IFN- $\gamma$ is likely contributing to migration of immune cells to the CNS. IL- $1 \beta$ may be further contributing to disease progression in MS patients. CFS/ME patients ex- 
hibited abnormal levels of IFN- $\gamma$, independent of IL-12 elevation. This may be either contributory or compensatory to the reduced NK activity observed in in CFS/ME patients.

\subsection{Th2 and Th17 Cytokines}

IL-10 was significantly elevated in both CFS/ME and MS patients. Previous studies have also found elevated levels of IL-10 in CFS/ME patients [8] [9]. There is evidence that IL-10 stimulates NK cell activation [45]. As mentioned previously, NK dysfunction is a consistent feature of CFS/ME. Hence the elevated levels of IL-10 in CFS/ME patients may be a consequence of NK dysfunction. It has been demonstrated that IL-10 production increases before and during remission in MS, and therefore the administration of IL-10 has been explored as a treatment option [46]. IL-10 is also secreted by Tregs upon stimulation by IL-2 [47]. In CFS/ME, elevated numbers of Tregs have been observed [48] [49], and high expression of Foxp3, which plays an important role in the development and function of Tregs, has also been observed [9]. This suggests that elevated levels of IL-10 may occur as a result of increases in Tregs, as Tregs are induced by and produce IL-10 [50]. Additionally a study examining spinal fluid abnormalities in CFS/ME patients reported elevated levels of IL-10 in CSF [51]. This may indicate inflammation in the CNS of CFS/ME patients. MS studies have also revealed dysfunctional Tregs in the CNS [52]-[54], which may be linked to the abnormal IL-10 levels. However in previous MS studies, levels of IL-10 were significantly decreased in patients, particularly those with high disease severity [55]-[57]. This suggests that MS patients in this study were not or are not currently experiencing high symptom severity, contradicting the presence of IFN- $\gamma$. This may be due to the IFN- $\beta$ treatment of MS, as it has been demonstrated that this causes increased IL-10 production [58].

The differentiation of naive B cells into antibody secreting plasma cells is profoundly influenced by IL-5, which is produced by Th2 and NK cells [59]. The elevated levels of IL-5 have been previously observed in CFS/ME patients [6] [10]. Similarly, B cells have been previously implicated in CFS/ME [60]. It has been suggested that depletion of B cells by Rituximab in CFS/ME patients results in repopulation of normalized B cell subsets, resetting the B cell compartment [61]. Furthermore, CFS/ME patients may have higher populations of transitional and naive B cell subsets, and in some cases reduced plasma B cells [61]. B cells are also important in MS. The discovery of autoantibodies against neuronal tissues indicates a pathogenic role of B cells in MS [62]. Additionally, treatment of MS patients with Rituximab reduced lesions and clinical relapses [63]. IL-5 has been associated with eosinophilic diseases such as asthma and allergies [64]. Importantly, there has been evidence of eosinophil activation in CFS/ME patients in the form of elevated eosinophil cationic proteins in the serum of CFS/ME patients [65]. EAE lesions are typically present in the spinal cord and optic nerves with large recruitment of granulocytes and eosinophils to the lesion sites [66], which may be associated with the elevated IL-5.

IL-4 stimulates antibody secretion by B cells and B cell proliferation and is a major regulatory cytokine [67]. MS patients exhibited significantly elevated serum levels, supporting previous findings [21] [22] [68]-[70]. CFS/ME patients demonstrated no significant difference in serum levels, as was also found in a previous study [9]. However previous research has also reported significantly elevated levels and production of IL-4 [6] [10] [71]. IL-13 is a T cell derived cytokines responsible for IgE class switching of B cells and inhibition of inflammatory cytokines [72]. CFS/ME patient samples were not significantly different from controls, however previously significantly decreased serum levels of IL-13 have been reported in CFS/ME [6] [10]. MS patients exhibited significantly elevated levels of IL-13 in serum samples compared to controls, which has also been previously reported [73]-[75]. IL-17 is secreted by Th17 cells, and is believed to induce the secretion of IL-6, IL-8, and GCSF, and may affect NK cell function [76]-[78]. Contrary to what was found in this study, decreased levels of IL-17 compared to controls have been observed in CFS/ME previously [8], however other studies also confirm the finding of no significant difference [6] [9] [10]. MS patients however exhibited significantly elevated serum levels of IL-17, supporting previous research [79] [80]. This was expected as it is well accepted that IL-17 plays an integral role in the pathophysiology of MS due to its high concentration in MS lesions and its role in EAE [76]. Lastly IL-6 is a multi-functional cytokine, acting as a B cell differentiation factor as well as an immune regulator and a facilitator of inflammation and the acute phase response [81]. Compared to healthy controls, CFS/ME patient serum levels of IL-6 were not significantly different, as found previously [11] [82]. However, other studies also found elevated levels of IL-6 in CFS/ME patients [6] [7]. In MS patients IL-6 was significantly elevated, confirming the findings of other previous studies [24] [25]. 
The significant alteration in IL-10 present in both CFS/ME and MS patients indicates a struggle to suppress overactive immune responses. Additionally, elevated levels of IL-5 in both conditions suggest a Th2 cytokine profile, and may serve to compensate for elevated Th1 cytokines levels and inflammation present in both CFS/ME and MS. In CFS/ME patients, IL-5 may be released by NK cells concurrently with IFN- $\gamma$. Additionally, IL-5, IL-4, and IL-6 may be contributing to pathogenic B cells in MS, through activation of B cell differentiation and antibody secretion. The elevation of IL-17 is indicative of Th17 involvement in MS pathology.

\subsection{Other Cytokines and Chemokines}

MS patients also exhibited elevated levels of IL-1r $\alpha$, IL-7, IL-9, eotaxin, IP-10, MIP1 $\alpha$, basic FGF, and GCSF. IL-1r $\alpha$ polymorphisms are been detected in genetic studies of MS patients [83]. IFN- $\beta$ treatment is believed to elevated serum levels of IL-1r $\alpha$ [84], hence the elevated levels may be due to IFN- $\beta$ treatment received by patients in the study. Similarly elevated IL-7 is a marker for IFN- $\beta$ treatment responsiveness [85]. Th2, Th17 and Tregs are responsible for the production of IL-9 [86], and neutralization of IL-9 by antibodies attenuates EAE [87]. Studies into eotaxin, an activator for eosinophils, have shown both elevation and decreased levels in the CSF of MS patients [88] [89], and suggested it is associated with MS relapse [90]. IP-10 influences angiogenesis and chemotaxis of a range of cells, including NK cells, T cells, macrophages and microglial cells [91]. Both IP-10 and its receptor have been detected in MS lesions [92], and elevated levels of IP-10 have been detected in MS serum [93]. It is believed that IP-10 plays a role in the recruitment of immune cells to lesions. MIP- $1 \alpha$ is also responsible for recruitment of immune cells including T cells, NK cells and macrophages, as well as stimulation of degranulation and phagocytosis [94]. MIP-1 $\alpha$ may also play a role in the recruitment of immune cells to lesions in MS [95]. The role of basic FGF in MS is debated, as there is evidence of it inhibiting remyelination in MS lesions [96] and contribution of recruitment of immune cells [97], as well as evidence of basic FGF exhibiting neuroprotective functions in EAE [98]. Lastly GCSF stimulates the production and maturation of granulocytes [99]. Elevation of GCSF is believed to contribute to increased number of primed neutrophils in MS [100] [101]. In this study CFS/ME patients did not exhibit any significant differences from controls for any of the above-mentioned cytokines, however previous research in CFS/ME of these cytokines is sparse with little to compare to. Further research to should conducted to verify these findings.

MS patients have exhibited elevated levels of chemotactic factors eotaxin, IP-10, and MIP- $1 \alpha$ suggest high migration of macrophages, T cells, B cells, and NK cells. As MS is a neurodegenerative disease, these immune cells are likely migrating towards the CNS. Hence these results suggest that patients may be in a state of relapse, with further recruitment of immune cells and potential worsening of disease. CFS/ME patients did not exhibit abnormal levels of these chemokines, indicating that chemotactic driven migration of immune cells was not present in these patients. CFS/ME patients also did not exhibit changes in growth factor production, unlike MS patients whose elevated expression may be compensatory to neural damage.

Expression of Th1 and Th2 cytokines were observed in both CFS/ME and MS. Th2 cytokine elevations may be a compensatory response to an overactive immune reaction. The findings of this study implicate widespread immune dysfunction in CFS/ME, through abnormal IFN- $\gamma$, IL-10 and IL-5 serum levels. Immune dysfunction may involve NK cells, Tregs, B cells and eosinophils, with potential similarities to MS pathophysiology. These provide potential areas for future research. However, many cytokines have not been sufficiently researched in CFS/ME outside of this study, and so further research should be conducted to investigate the roles of these cytokines in CFS/ME. The cytokines that were abnormally elevated in MS patients were consistent with those associated with disease, and are indicative of high disease severity. However, some of the elevations of cytokines may have been influenced by IFN- $\beta$ treatment.

\section{Conclusion}

In conclusion, this study has reported expression of Th1 and Th2 cytokines in CFS/ME and MS patients. Elevated levels of IFN- $\gamma$, IL-10 and IL-5 were found in both CFS/ME and MS. In the MS cohort, the results were consistent with the majority of findings from previous studies, where general elevation of pro-inflammatory, some anti-inflammatory, Th1 and Th2 cytokines has been observed [102]. However, results for CFS/ME cytokine levels, including IFN- $\gamma$ [37] [103], IL-10 [6] [10], IL-17 [8], and IL-12 [6] [8], conflicted with previous findings. This is likely due to the heterogeneity of CFS/ME [102]. Additionally the use of the ICC [1] as opposed to the more commonly used 1994 CDC definition [104], may have played a role in differential results. A 
study comparing the results of cytokines across differing definitions could help resolve conflicting findings of previous studies. Additionally different subgroups of CFS/ME, based on symptomology and severity, may present with differing cytokine profiles, and this may be an area for future research. A longitudinal study with multiple time points would be more suitable to assess cytokine profiles. Furthermore isolation of immune cells to determine specific cytokine secretion from different cell types may provide more detailed insight into CFS/ME pathophysiology. Lastly CFS/ME patients are known to administer multiple medications, which may affect cytokine secretion. Analysis of these interactions and effects could be an important area for further research.

\section{Acknowledgements}

We would like to acknowledge the Mason Foundation (Grant Number MA43120) and Queensland Government Department of Science, Information Technology, Innovation and the Arts Smart Futures Fund (Grant Number 216702MRE) for the founding of this project.

\section{Competing Interest}

Authors would like to disclose there are no competing interests.

\section{References}

[1] Carruthers, B.M., et al. (2011) Myalgic Encephalomyelitis: International Consensus Criteria. Journal of Internal Medicine, 270, 326-338. http://dx.doi.org/10.1111/j.1365-2796.2011.02428.x

[2] Hiscott, J. and Ware, C. (2011) Cytokines. Current Opinion in Immunology, 23, 561-563. http://dx.doi.org/10.1016/j.coi.2011.09.001

[3] Lloyd, A., et al. (1992) Cell-Mediated Immunity in Patients with Chronic Fatigue Syndrome, Healthy Control Subjects and Patients with Major Depression. Clinical \& Experimental Immunology, 87, 76-79. http://dx.doi.org/10.1111/j.1365-2249.1992.tb06416.x

[4] Peakman, M., et al. (1997) Clinical Improvement in Chronic Fatigue Syndrome Is Not Associated with Lymphocyte Subsets of Function or Activation. Clinical Immunology and Immunopathology, 82, 83-91. http://dx.doi.org/10.1006/clin.1996.4284

[5] Rasmussen, A., et al. (1994) Chronic Fatigue Syndrome-A Controlled Cross-Sectional Study. Ugeskrift for Laeger, 156, 6836-6840.

[6] Fletcher, M.A., et al. (2009) Plasma Cytokines in Women with Chronic Fatigue Syndrome. Journal of Translational Medicine, 7, 96. http://dx.doi.org/10.1186/1479-5876-7-96

[7] Chao, C.C., et al. (1991) Altered Cytokine Release in Peripheral Blood Mononuclear Cell Cultures from Patients with the Chronic Fatigue Syndrome. Cytokine, 3, 292-298. http://dx.doi.org/10.1016/1043-4666(91)90497-2

[8] Brenu, E., et al. (2012) Longitudinal Investigation of Natural Killer Cells and Cytokines in Chronic Fatigue Syndrome/ Myalgic Encephalomyelitis. Journal of Translational Medicine, 10, 88. http://dx.doi.org/10.1186/1479-5876-10-88

[9] Brenu, E., et al. (2011) Immunological Abnormalities as Potential Biomarkers in Chronic Fatigue Syndrome/Myalgic Encephalomyelitis. Journal of Translational Medicine, 9, 81. http://dx.doi.org/10.1186/1479-5876-9-81

[10] Broderick, G., et al. (2010) A Formal Analysis of Cytokine Networks in Chronic Fatigue Syndrome. Brain, Behavior, and Immunity, 24, 1209-1217. http://dx.doi.org/10.1016/j.bbi.2010.04.012

[11] Patarca, R., Klimas, N.G., Lugtendorf, S., et al. (1994) Dysregulated Expression of Tumor Necrosis Factor in Chronic Fatigue Syndrome: Interrelations with Cellular Sources and Patterns of Soluble Immune Mediator Expression. Clinical Infectious Diseases, 18, S147-S153. http://dx.doi.org/10.1093/clinids/18.supplement_1.s147

[12] Cheney, P.R., Dorman, S.E. and Bell, D.S. (1989) Interleukin-2 and the Chronic Fatigue Syndrome. Annals of Internal Medicine, 110, 321-321. http://dx.doi.org/10.7326/0003-4819-110-4-321_1

[13] Ashwani, A. (2010) Multiple Sclerosis: A Review. International Journal of Pharmaceutical Sciences and Research, 1, 13.

[14] Compstom, A. and Coles, A. (2008) Multiple Sclerosis. The Lancet, 372, 1507-1517.

[15] Hauser, S.L. and Oksenberg, J.R. (2006) The Neurobiology of Multiple Sclerosis: Genes, Inflammation, and Neurodegeneration. Neuron, 52, 61-76. http://dx.doi.org/10.1016/j.neuron.2006.09.011

[16] Lublin, F.D. and Reingold, S.C. (1996) Defining the Clinical Course of Multiple Sclerosis Results of an International Survey. Neurology, 46, 907-911. http://dx.doi.org/10.1212/WNL.46.4.907 
[17] Panitch, H., Hirsch, R.L., Haley, A.S., et al. (1987) Exacerbations of Multiple Sclerosis in Patients Treated with Gamma Interferon. The Lancet, 329, 893-895. http://dx.doi.org/10.1016/S0140-6736(87)92863-7

[18] Beck, J., Rondot, P., Catinot, L., et al. (1988) Increased Production of Interferon Gamma and Tumor Necrosis Factor Precedes Clinical Manifestation in Multiple Sclerosis: Do Cytokines Trigger off Exacerbations? Acta Neurologica Scandinavica, 78, 318-323. http://dx.doi.org/10.1111/j.1600-0404.1988.tb03663.x

[19] Selmaj, K., Raine, C.S., Cannella, B. and Brosnan, C.F. (1991) Identification of Lymphotoxin and Tumor Necrosis Factor in Multiple Sclerosis Lesions. Journal of Clinical Investigation, 87, 949. http://dx.doi.org/10.1172/jci115102

[20] Zipp, F., Weber, F., Huber, S., et al. (1995) Genetic Control of Multiple Sclerosis: Increased Production of Lymphotoxin and Tumor Necrosis Factor- $\alpha$ by HLA-DR2 ${ }^{+}$T Cells. Annals of Neurology, 38, 723-730. http://dx.doi.org/10.1002/ana.410380506

[21] Imitola, J., Chitnis, T. and Khoury, S.J. (2005) Cytokines in Multiple Sclerosis: From Bench to Bedside. Pharmacology \& Therapeutics, 106, 163-177. http://dx.doi.org/10.1016/j.pharmthera.2004.11.007

[22] Cannella, B. and Raine, C.S. (1995) The Adhesion Molecule and Cytokine Profile of Multiple Sclerosis Lesions. Annals of Neurology, 37, 424-435. http://dx.doi.org/10.1002/ana.410370404

[23] Smith, D.R., Balashov, K.E., Hafler, D.A., et al. (1997) Immune Deviation Following Pulse Cyclophosphamide/Methylprednisolone Treatment of Multiple Sclerosis: Increased Interleukin-4 Production and Associated Eosinophilia. Annals of Neurology, 42, 313-318. http://dx.doi.org/10.1002/ana.410420307

[24] Stelmasiak, Z., Kozioł-Montewka, M., Dobosz, B., et al. (2000) Interleukin-6 Concentration in Serum and Cerebrospinal Fluid in Multiple Sclerosis Patients. Medical Science Monitor, 6, 1104-1108.

[25] Chen, Y.-C., Yang, X., Miao, L., et al. (2012) Serum Level of Interleukin-6 in Chinese Patients with Multiple Sclerosis. Journal of Neuroimmunology, 249, 109-111. http://dx.doi.org/10.1016/j.jneuroim.2012.04.015

[26] Rieckmann, P., Albrecht, M., Kitze, B., et al. (1994) Cytokine mRNA Levels in Mononuclear Blood Cells from Patients with Multiple Sclerosis. Neurology, 44, 1523-1523. http://dx.doi.org/10.1212/WNL.44.8.1523

[27] Correale, J., Gilmore, W., McMillan, M., et al. (1995) Patterns of Cytokine Secretion by Autoreactive Proteolipid Protein-Specific T Cell Clones during the Course of Multiple Sclerosis. The Journal of Immunology, 154, 2959-2968.

[28] Correale, J., McMillan, M., McCarthy, K., Le, T., Weiner, L.P., et al. (1995) Isolation and Characterization of Autoreactive Moteolioid Protein-Peptide Specific T-Cell Clones from Multiple Sclerosis Patients. Neurology, 45, 13701375. http://dx.doi.org/10.1212/WNL.45.7.1370

[29] Pelfrey, C.M., Rudick, R.A., Cotleur, A.C., et al. (2000) Quantification of Self-Recognition in Multiple Sclerosis by Single-Cell Analysis of Cytokine Production. The Journal of Immunology, 165, 1641-1651. http://dx.doi.org/10.4049/jimmunol.165.3.1641

[30] Polman, C.H., Reingold, S.C., Banwell, B., et al. (2011) Diagnostic Criteria for Multiple Sclerosis: 2010 Revisions to the McDonald Criteria. Annals of Neurology, 69, 292-302. http://dx.doi.org/10.1002/ana.22366

[31] Laurikkala, J., et al. (2000) Informal Identification of Outliers in Medical Data. Proceedings of the Fifth International Workshop on Intelligent Data Analysis in Medicine and Pharmacology, Berlin, 22 August 2000.

[32] Patarca, R. (2001) Cytokines and Chronic Fatigue Syndrome. Annals of the New York Academy of Sciences, 933, 185200. http://dx.doi.org/10.1111/j.1749-6632.2001.tb05824.x

[33] Young, H.A. and Hardy, K.J. (1995) Role of Interferon-Gamma in Immune Cell Regulation. Journal of Leukocyte Biology, 58, 373-381.

[34] Bradley, L., Dalton, D. and Croft, M. (1996) A Direct Role for IFN-Gamma in Regulation of Th1 Cell Development. Journal of Immunology, 157, 1350-1358.

[35] Kibler, R., Lucas, D.O., Hicks, M.J., et al. (1985) Immune Function in Chronic Active Epstein-Barr Virus Infection. Journal of Clinical Immunology, 5, 46-54. http://dx.doi.org/10.1007/BF00915168

[36] Brenu, E., Staines, D.R., Baskurt, O.K., et al. (2010) Immune and Hemorheological Changes in Chronic Fatigue Syndrome. Journal of Translational Medicine, 8, 1.

[37] Klimas, N.G., Morgan, R., Fletcher, M.A., et al. (1990) Immunologic Abnormalities in Chronic Fatigue Syndrome. Journal of Clinical Microbiology, 28, 1403-1410.

[38] Levine, P.H., Whiteside, T.L., Friberg, D., et al. (1998) Dysfunction of Natural Killer Activity in a Family with Chronic Fatigue Syndrome. Clinical Immunology and Immunopathology, 88, 96-104. http://dx.doi.org/10.1006/clin.1998.4554

[39] Issazadeh, S., Ljungdahl, A., Höjeberg, B., et al. (1995) Cytokine Production in the Central Nervous System of Lewis Rats with Experimental Autoimmune Encephalomyelitis: Dynamics of mRNA Expression for Interleukin-10, Interleukin-12, Cytolysin, Tumor Necrosis Factor $\alpha$ and Tumor Necrosis Factor $\beta$. Journal of Neuroimmunology, 61, 205-212. 
http://dx.doi.org/10.1016/0165-5728(95)00100-G

[40] Pokryszko-Dragan, A., Frydecka, I., Kosmaczewska, A., et al. (2012) Stimulated Peripheral Production of InterferonGamma Is Related to Fatigue and Depression in Multiple Sclerosis. Clinical Neurology and Neurosurgery, 114, 11531158. http://dx.doi.org/10.1016/j.clineuro.2012.02.048

[41] Seppia, D., Puthenparampil, M., Federle, L., et al. (2014) Cerebrospinal Fluid IL-1 $\beta$ Correlates with Cortical Pathology Load in Multiple Sclerosis at Clinical Onset. Journal of Neuroimmunology, 270, 56-60. http://dx.doi.org/10.1016/j.jneuroim.2014.02.014

[42] Takahashi, J.L., Giuliani, F., Power, C., et al. (2003) Interleukin-1 $\beta$ Promotes Oligodendrocyte Death through Glutamate Excitotoxicity. Annals of Neurology, 53, 588-595. http://dx.doi.org/10.1002/ana.10519

[43] Vignali, D.A.A. and Kuchroo, V.K. (2012) IL-12 Family Cytokines: Immunological Playmakers. Nature Immunology, 13, 722-728. http://dx.doi.org/10.1038/ni.2366

[44] Windhagen, A., Newcombe, J., Dangond, F., et al. (1995) Expression of Costimulatory Molecules B7-1 (CD80), B7-2 (CD86), and Interleukin 12 Cytokine in Multiple Sclerosis Lesions. The Journal of Experimental Medicine, 182, 19851996. http://dx.doi.org/10.1084/jem.182.6.1985

[45] Mocellin, S., Panelli, M.C., Wang, E., et al. (2003) The Dual Role of IL-10. Trends in Immunology, 24, 36-43. http://dx.doi.org/10.1016/S1471-4906(02)00009-1

[46] Hohnoki, K., Inoue, A. and Koh, C.-S. (1998) Elevated Serum Levels of IFN- $\gamma$, IL-4 and TNF- $\alpha$ Unelevated Serum Levels of IL-10 in Patients with Demyelinating Diseases during the Acute Stage. Journal of Neuroimmunology, 87, 2732. http://dx.doi.org/10.1016/S0165-5728(98)00053-8

[47] Scheffold, A., Murphy, K.M. and Höfer, T. (2007) Competition for Cytokines: Treg Cells Take All. Nature Immunology, 8, 1285-1287. http://dx.doi.org/10.1038/ni1207-1285

[48] Brenu, E., Huth, T.K., Hardcastle, S.L., et al. (2014) Role of Adaptive and Innate Immune Cells in Chronic Fatigue Syndrome/Myalgic Encephalomyelitis. International Immunology, 26, 233. http://dx.doi.org/10.1093/intimm/dxt068

[49] Curriu, M., Carrillo, J., Massanella, M., et al. (2013) Screening NK-, B- and T-Cell Phenotype and Function in Patients Suffering from Chronic Fatigue Syndrome. Journal of Translational Medicine, 11, 68. http://dx.doi.org/10.1186/1479-5876-11-68

[50] Couper, K.N., Blount, D.G. and Riley, E.M. (2008) IL-10: The Master Regulator of Immunity to Infection. The Journal of Immunology, 180, 5771-5777. http://dx.doi.org/10.4049/jimmunol.180.9.5771

[51] Natelson, B.H., Weaver, S.A., Tseng, C.L., et al. (2005) Spinal Fluid Abnormalities in Patients with Chronic Fatigue Syndrome. Clinical and Diagnostic Laboratory Immunology, 12, 52-55. http://dx.doi.org/10.1128/cdli.12.1.52-55.2005

[52] Venken, K., Hellings, N., Thewissen, M., et al. (2008) Compromised CD4 ${ }^{+}$CD25 ${ }^{\text {high }}$ Regulatory T-Cell Function in Patients with Relapsing-Remitting Multiple Sclerosis Is Correlated with a Reduced Frequency of FOXP3-Positive Cells and Reduced FOXP3 Expression at the Single-Cell Level. Immunology, 123, 79-89. http://dx.doi.org/10.1111/j.1365-2567.2007.02690.x

[53] Venken, K., Hellings, N., Hensen, K., et al. (2006) Secondary Progressive in Contrast to Relapsing-Remitting Multiple Sclerosis Patients Show a Normal CD4 ${ }^{+} \mathrm{CD} 25^{+}$Regulatory T-Cell Function and FOXP3 Expression. Journal of Neuroscience Research, 83, 1432-1446. http://dx.doi.org/10.1002/jnr.20852

[54] Venken, K., Hellings, N., Broekmans, T., et al. (2008) Natural Naive CD4 ${ }^{+}$CD25 $5^{+}$CD127low Regulatory T Cell (Treg) Development and Function Are Disturbed in Multiple Sclerosis Patients: Recovery of Memory Treg Homeostasis during Disease Progression. The Journal of Immunology, 180, 6411-6420. http://dx.doi.org/10.4049/jimmunol.180.9.6411

[55] Soldan, S.S., Alvarez Retuerto, A.I., Sicotte, N.L., et al. (2004) Dysregulation of IL-10 and IL-12p40 in Secondary Progressive Multiple Sclerosis. Journal of Neuroimmunology, 146, 209-215. http://dx.doi.org/10.1016/j.jneuroim.2003.10.033

[56] Michel, L., Degauque, N., Garcia, A., et al. (2011) Loss of IL-10 Secretion by Regulatory B Lymphocytes in Multiple Sclerosis Patients. Journal of Translational Medicine, 9, 25-25. http://dx.doi.org/10.1186/1479-5876-9-S2-P25

[57] Huang, W.-X., Huang, P., Link, H. and Hillert, J. (1999) Cytokine Analysis in Multiple Sclerosis by Competitive RTPCR: A Decreased Expression of IL-10 and an Increased Expression of TNF- $\alpha$ in Chronic Progression. Multiple Sclerosis, 5, 342-348.

[58] Tuohy, V.K., Yu, M., Yin, L., et al. (2000) Modulation of the IL-10/IL-12 Cytokine Circuit by Interferon-Beta Inhibits the Development of Epitope Spreading and Disease Progression in Murine Autoimmune Encephalomyelitis. Journal of Neuroimmunology, 111, 55. http://dx.doi.org/10.1016/S0165-5728(00)00384-2

[59] Takatsu, K. (2011) Interleukin-5 and IL-5 Receptor in Health and Diseases. Proceedings of the Japan Academy Series B, Physical and Biological Sciences, 87, 463-485. http://dx.doi.org/10.2183/pjab.87.463

[60] Fluge, Ø., Bruland, O., Risa, K., et al. (2011) Benefit from B-Lymphocyte Depletion Using the Anti-CD20 Antibody 
Rituximab in Chronic Fatigue Syndrome. A Double-Blind and Placebo-Controlled Study. PLoS ONE, 6, e26358. http://dx.doi.org/10.1371/journal.pone.0026358

[61] Bradley, A., Ford, B. and Bansal, A. (2013) Altered Functional B Cell Subset Populations in Patients with Chronic Fatigue Syndrome Compared to Healthy Controls. Clinical and Experimental Immunology, 172, 73-80. http://dx.doi.org/10.1111/cei.12043

[62] Franciotta, D., Salvetti, M., Lolli, F., et al. (2008) B Cells and Multiple Sclerosis. Lancet Neurology, 7, 852-858. http://dx.doi.org/10.1016/S1474-4422(08)70192-3

[63] Hauser, S.L., Waubant, E., Arnold, D.L., et al. (2008) B-Cell Depletion with Rituximab in Relapsing-Remitting Multiple Sclerosis. The New England Journal of Medicine, 358, 676-688. http://dx.doi.org/10.1056/NEJMoa0706383

[64] Corren, J. (2012) Inhibition of Interleukin-5 for the Treatment of Eosinophilic Diseases. Discovery Medicine, 13, 305312.

[65] Conti, F., Priori, R., Valesini, G., et al. (1996) Eosinophil Cationic Protein Serum Levels and Allergy in Chronic Fatigue Syndrome. Allergy, 51, 124-127. http://dx.doi.org/10.1111/j.1398-9995.1996.tb00047.x

[66] Lassmann, H. and Ransohoff, R.M. (2004) The CD4-Th1 Model for Multiple Sclerosis: A Crucial Re-Appraisal. Trends in Immunology, 25, 132-137. http://dx.doi.org/10.1016/j.it.2004.01.007

[67] Oleksowicz, L. and Dutcher, J.P. (1994) A Review of the New Cytokines: IL-4, IL-6, IL-11, and IL-12. American Journal of Therapeutics, 1, 107-115. http://dx.doi.org/10.1097/00045391-199408000-00002

[68] Hohnoki, K., Inoue, A. and Koh, C.-S. (1998) Elevated Serum Levels of IFN- $\gamma$, IL-4 and TNF- $\alpha$ Unelevated Serum Levels of IL-10 in Patients with Demyelinating Diseases during the Acute Stage. Journal of Neuroimmunology, 87, 2732. http://dx.doi.org/10.1016/S0165-5728(98)00053-8

[69] Link, J., Söderström, M., Olsson, T., et al. (1994) Increased Transforming Growth Factor- $\beta$, Interleukin-4, and Interferon- $\gamma$ in Multiple Sclerosis. Annals of Neurology, 36, 379-386. http://dx.doi.org/10.1002/ana.410360309

[70] Bartosik-Psujek, H. and Stelmasiak, Z. (2005) Correlations between IL-4, IL-12 Levels and CCL2, CCL5 Levels in Serum and Cerebrospinal Fluid of Multiple Sclerosis Patients. Journal of Neural Transmission, 112, 797-803. http://dx.doi.org/10.1007/s00702-004-0225-9

[71] Skowera, A., Cleare, A., Blair, D., et al. (2004) High Levels of Type 2 Cytokine-Producing Cells in Chronic Fatigue Syndrome. Clinical \& Experimental Immunology, 135, 294-302. http://dx.doi.org/10.1111/j.1365-2249.2004.02354.X

[72] Wynn, T.A. (2003) IL-13 Effector Functions. Annual Review of Immunology, 21, 425-456. http://dx.doi.org/10.1146/annurev.immunol.21.120601.141142

[73] Martins, T.B., Rose, J.W., Jaskowski, T.D., et al. (2011) Analysis of Proinflammatory and Anti-Inflammatory Cytokine Serum Concentrations in Patients with Multiple Sclerosis by Using a Multiplexed Immunoassay. American Journal of Clinical Pathology, 136, 696-704. http://dx.doi.org/10.1309/AJCP7UBK8IBVMVNR

[74] Musabak, U., Demirkaya, S., Genç, G., et al. (2011) Serum Adiponectin, TNF- $\alpha$, IL-12p70, and IL-13 Levels in Multiple Sclerosis and the Effects of Different Therapy Regimens. Neuroimmunomodulation, 18, 57-66. http://dx.doi.org/10.1159/000317393

[75] Rossi, S., Mancino, R., Bergami, A., et al. (2011) Potential Role of IL-13 in Neuroprotection and Cortical Excitability Regulation in Multiple Sclerosis. Multiple Sclerosis, 17, 1301-1312. http://dx.doi.org/10.1177/1352458511410342

[76] Korn, T., Bettelli, E., Oukka, M., et al. (2009) IL-17 and Th17 Cells. Annual Review of Immunology, 27, 485-517. http://dx.doi.org/10.1146/annurev.immunol.021908.132710

[77] Gaffen, S.L. (2008) An Overview of IL-17 Function and Signaling. Cytokine, 43, 402-407. http://dx.doi.org/10.1016/j.cyto.2008.07.017

[78] Al Omar, S., Flanagan, B.F., Almehmadi, M. and Christmas, S.E. (2013) The Effects of IL-17 upon Human Natural Killer Cells. Cytokine, 62, 123-130. http://dx.doi.org/10.1016/j.cyto.2013.02.005

[79] Chen, Y.-C., Chen, S.D., Miao, L., et al. (2012) Serum Levels of Interleukin (IL)-18, IL-23 and IL-17 in Chinese Patients with Multiple Sclerosis. Journal of Neuroimmunology, 243, 56-60. http://dx.doi.org/10.1016/j.jneuroim.2011.12.008

[80] Kawanokuchi, J., Shimizu, K., Nitta, A., et al. (2008) Production and Functions of IL-17 in Microglia. Journal of Neuroimmunology, 194, 54-61. http://dx.doi.org/10.1016/j.jneuroim.2007.11.006

[81] Ishihara, K. and Hirano, T. (2002) IL-6 in Autoimmune Disease and Chronic Inflammatory Proliferative Disease. Cytokine \& Growth Factor Reviews, 13, 357-368. http://dx.doi.org/10.1016/S1359-6101(02)00027-8

[82] Linde, A., Andersson, B., Svenson, S.B., et al. (1992) Serum Levels of Lymphokines and Soluble Cellular Receptors in Primary Epstein-Barr Virus Infection and in Patients with Chronic Fatigue Syndrome. Journal of Infectious Diseases, 165, 994-1000. http://dx.doi.org/10.1093/infdis/165.6.994 
[83] Laine, M.L., Farré, M.A., Crusius, J.B.A., et al. (2000) The Mouthwash: A Non-Invasive Sampling Method to Study Cytokine Gene Polymorphisms. Journal of Periodontology, 71, 1315-1318. http://dx.doi.org/10.1902/jop.2000.71.8.1315

[84] Nicoletti, F., Patti, F., DiMarco, R., et al. (1996) Circulating Serum Levels of IL-1ra in Patients with Relapsing Remitting Multiple Sclerosis Are Normal during Remission Phases but Significantly Increased Either during Exacerbations or in Response to IFN- $\beta$ Treatment. Cytokine, 8, 395-400. http://dx.doi.org/10.1006/cyto.1996.0054

[85] Graber, J.J. and Dhib-Jalbut, S. (2014) Biomarkers of Interferon Beta Therapy in Multiple Sclerosis. Journal of Interferon \& Cytokine Research: The Official Journal of the International Society for Interferon and Cytokine Research, 34, 600-604. http://dx.doi.org/10.1089/jir.2013.0144

[86] Goswami, R. and Kaplan, M.H. (2011) A Brief History of IL-9. Journal of Immunology, 186, 3283-3288.

[87] Nowak, E.C., Weaver, C.T., Turner, H., et al. (2009) IL-9 as a Mediator of Th17-Driven Inflammatory Disease. The Journal of Experimental Medicine, 206, 1653-1660. http://dx.doi.org/10.1084/jem.20090246

[88] Franciotta, D., Zardini, E., Ravaglia, S., et al. (2006) Cytokines and Chemokines in Cerebrospinal Fluid and Serum of Adult Patients with Acute Disseminated Encephalomyelitis. Journal of the Neurological Sciences, 247, 202-207. http://dx.doi.org/10.1016/j.jns.2006.05.049

[89] Narikawa, K., Misu, T., Fujihara, K., et al. (2004) CSF Chemokine Levels in Relapsing Neuromyelitisoptica and Multiple Sclerosis. Journal of Neuroimmunology, 149, 182-186. http://dx.doi.org/10.1016/j.jneuroim.2003.12.010

[90] Öckinger, J., Stridh, P., Beyeen, A.D., et al. (2009) Genetic Variants of CC Chemokine Genes in Experimental Autoimmune Encephalomyelitis, Multiple Sclerosis and Rheumatoid Arthritis. Genes and Immunity, 11, 142-154. http://dx.doi.org/10.1038/gene.2009.82

[91] Liu, M., Guo, S., Hibbert, J.M., et al. (2011) CXCL10/IP-10 in Infectious Diseases Pathogenesis and Potential Therapeutic Implications. Cytokine and Growth Factor Reviews, 22, 121-130. http://dx.doi.org/10.1016/j.cytogfr.2011.06.001

[92] Trebst, C. and Ransohoff, R.M. (2001) Investigating Chemokines and Chemokine Receptors in Patients with Multiple Sclerosis: Opportunities and Challenges. Archives of Neurology, 58, 1975-1980. http://dx.doi.org/10.1001/archneur.58.12.1975

[93] Scarpini, E., Galimberti, D., Baron, P., et al. (2002) IP-10 and MCP-1 Levels in CSF and Serum from Multiple Sclerosis Patients with Different Clinical Subtypes of the Disease. Journal of the Neurological Sciences, 195, 41-46. http://dx.doi.org/10.1016/S0022-510X(01)00680-3

[94] Maurer, M. and Von Stebut, E. (2004) Macrophage Inflammatory Protein-1. The International Journal of Biochemistry \& Cell Biology, 36, 1882-1886. http://dx.doi.org/10.1016/j.biocel.2003.10.019

[95] Simpson, J.E., Newcombe, J., Cuzner, M.L. and Woodroofe, M.N. (1998) Expression of Monocyte Chemoattractant Protein-1 and Other Beta-Chemokines by Resident Glia and Inflammatory Cells in Multiple Sclerosis Lesions. Journal of Neuroimmunology, 84, 238-249. http://dx.doi.org/10.1016/S0165-5728(97)00208-7

[96] Goddard, D.R., Berry, M., Kirvell, S.L., et al. (2001) Fibroblast Growth Factor-2 Inhibits Myelin Production by Oligodendrocytes in Vivo. Molecular and Cellular Neuroscience, 18, 557-569. http://dx.doi.org/10.1006/mcne.2001.1025

[97] Clemente, D., Ortega, M.C., Arenzana, F.J., et al. (2011) FGF-2 and Anosmin-1 Are Selectively Expressed in Different Types of Multiple Sclerosis Lesions. The Journal of Neuroscience, 31, 14899-14909. http://dx.doi.org/10.1523/JNEUROSCI.1158-11.2011

[98] Rottlaender, A., Villwock, H., Addicks, K. and Kuerten, S. (2011) Neuroprotective Role of Fibroblast Growth Factor-2 in Experimental Autoimmune Encephalomyelitis. Immunology, 133, 370-378. http://dx.doi.org/10.1111/j.1365-2567.2011.03450.x

[99] Hamilton, J.A. (2008) Colony-Stimulating Factors in Inflammation and Autoimmunity. Nature Reviews. Immunology, 8, 533-544. http://dx.doi.org/10.1038/nri2356

[100] Debruyne, J., Philippe, J., Dereuck, J., et al. (1998) Relapse Markers in Multiple Sclerosis: Are in Vitro Cytokine Production Changes Reflected by Circulatory T-Cell Phenotype Alterations? Multiple Sclerosis, 4, 193-197. http://dx.doi.org/10.1177/135245859800400320

[101] Naegele, M., Tillack, K., Reinhardt, S., et al. (2012) Neutrophils in Multiple Sclerosis Are Characterized by a Primed Phenotype. Journal of Neuroimmunology, 242, 60-71. http://dx.doi.org/10.1016/j.jneuroim.2011.11.009

[102] Morris, G. and Maes, M. (2013) Myalgic Encephalomyelitis/Chronic Fatigue Syndrome and Encephalomyelitis Disseminata/Multiple Sclerosis Show Remarkable Levels of Similarity in Phenomenology and Neuroimmune Characteristics. BMC Medicine, 11, 205. http://dx.doi.org/10.1186/1741-7015-11-205

[103] Visser, J., Blauw, B., Hinloopen, B., et al. (1998) CD4 T Lymphocytes from Patients with Chronic Fatigue Syndrome Have Decreased Interferon-Gamma Production and Increased Sensitivity to Dexamethasone. The Journal of Infectious 
Diseases, 177, 451-454. http://dx.doi.org/10.1086/517373

[104] Fukuda, K., Straus, S.E., Hickie, I., et al. (1994) The Chronic Fatigue Syndrome: A Comprehensive Approach to Its Definition and Study. Annals of Internal Medicine, 121, 953-959.

http://dx.doi.org/10.7326/0003-4819-121-12-199412150-00009 